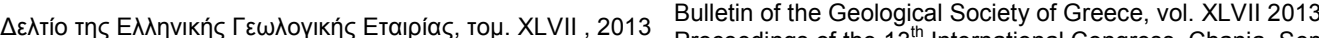
$\Delta \varepsilon \lambda$ ing $13^{\text {th }}$ International Congress, Chania, Sept.

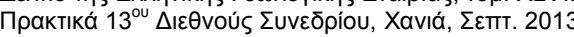
2013

\title{
NATURAL AND HUMAN HAZARD ASSESSMENT OF THE ARCHAEOLOGICAL SITES OF PAPHOS AREA (CYPRUS) WITH THE USE OF REMOTE SENSING AND GIS
}

\author{
Alexakis D. D. ${ }^{1}$, Agapiou A. ${ }^{2}$, Themistocleous K. ${ }^{1}$, Lysandrou V. ${ }^{2}$, Sarris A. ${ }^{3}$ \\ and Hadjimitsis D.G. \\ ${ }^{1}$ Department of Civil Engineering and Geomatics, Remote Sensing and Geo-environment Lab, \\ School of Engineering and Technology, Cyprus University of Technology,2-8 Saripolou Str., \\ Lemesos, Cyprus \\ dimitrios.alexakis@cut.ac.cy,athos.agapiou@cut.ac.cy,kt33@cytanet.com.cy, \\ d.hadjimitsis@cut.ac.cy \\ ${ }^{2}$ Museum of Kykkos, Cyprus, vaslysandrou@yahoo.it \\ ${ }^{3}$ Institute for Mediterranean Studies, Foundation for Research and Technology - Hellas (FORTH) \\ asaris@ret.forthnet.gr
}

\begin{abstract}
The study focuses on the creation of an innovative methodology for the development of a risk assessment model for the archaeological sites of western Cyprus (Paphos district). On site observation is the most common way for monitoring cultural heritage sites and monuments in Cyprus. However, this procedure which includes data collection, periodical observations, and multivariate risk assessment analysis, is practically difficult to be accomplished with the traditional practices and methods since it is time consuming and cost insufficient. Thus, the use of modern technologies such as Remote Sensing and GIS is anticipated to provide a tool of directives for the protection and preservation of cultural heritage sites from anthropogenic and environmental threats. These technologies provide to scientists integrated monitoring capabilities and have the unique advantage to store and manipulate a large amount of spatial and attribute data simultaneously. This study aims to integrate both satellite remote sensing techniques and GIS in a multidisciplinary approach, for monitoring natural and anthropogenic hazards with the use of archived and up-to-dated multi-temporal remotely sensed images in the study area, namely in areas nearby cultural heritage sites and monuments in Paphos area (Cyprus).According to the results, extensive construction and building development has taken placein the broader area. It was also proved that vast number of sites is established on areas prone to erosion and landslide phenomena
\end{abstract}

Key words: Erosion, Landslides, Cultural Heritage, Urban Sprawl.

\section{Пєрí $\lambda \psi \eta$}

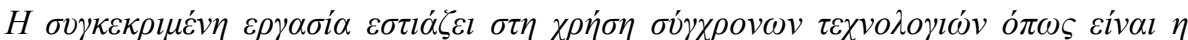

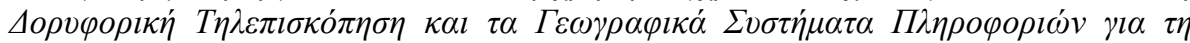

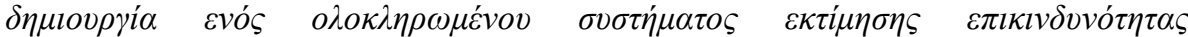

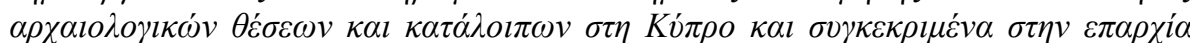

$\underline{\text { XLVII. No } 3-1448}$ 


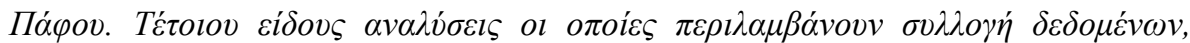

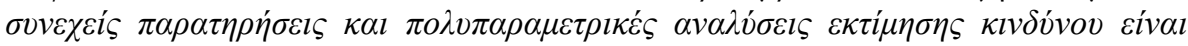

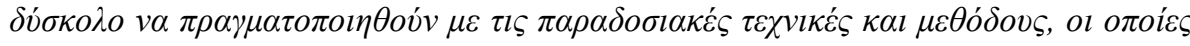

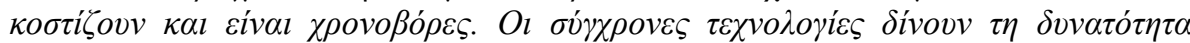

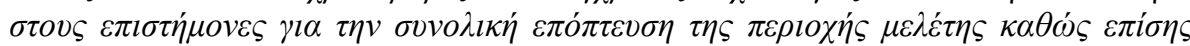

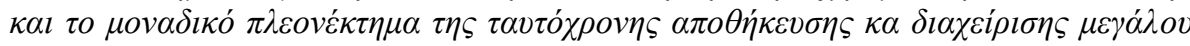

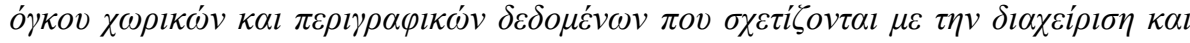

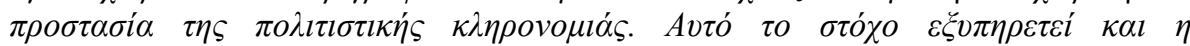

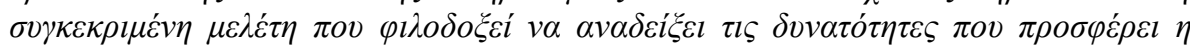

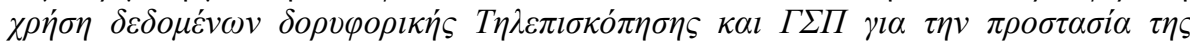

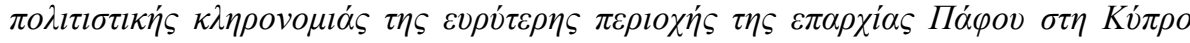

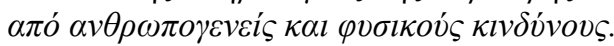

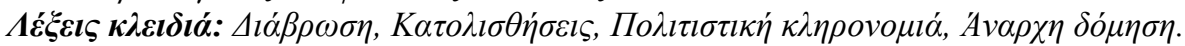

\section{Introduction}

Nowadays it has become obvious that in situ conservation of the archaeological heritage is endangered by different environmental and human factors such as landfills, erosion and urban sprawl (Carlon et al, 2002). Environmental, climatic changes and forces of nature, coupled with the anthropogenic interventions, increase the decay of archaeological remains. Both, the severe damages that most of these sites have suffered in the past and the accelerating pace of urban expansion within the last few decades, have made the protection of cultural heritage sites an essential task. Satellite remote sensing and Geographical Information Systems (GIS) can be employed to combine several different environmental and anthropogenic factors in order to proceed to the construction of a risk assessment model that could hierarchically classify an area of interest to different risk zones (Sarris, 2002; Alexakis et al., 2012; Agapiou et al., 2012; Themistocleous et al., 2012; Hadjimitsis et al., 2012). The use of GIS provides an effective methodology for an integrated analysis based on spatial information and the intrinsic and external parameters of a future instability (Canuti et al, 2000).

\section{Study Area and Data}

\subsection{Study Area}

The Paphos district is located in the SW part of Cyprus (Figure 1a). Several important monuments such as the Nea Paphos and the Tombs of the Kings archaeological sites, listed by UNESCO as World Heritage Monuments, are found in the broader area (Figure 2a). Paphos District was selected as the study area, since it combines both World Heritage Monuments, but in the same time one can find isolated monuments in the most in-accessible sites. Moreover monuments and sites in Paphos can be found both in urban and rural areas, near and far from the coastlines, in forest, or in industrial zones etc (Figure 1b). The urban sprawl pheromenon and the erosion hazard vulnerability were studied for all Paphos district. Concerning landslides hazard, the study area is located in the eastern part of Paphos district in the broader area of Statos and Ayios Photios villages, an area of $1393 \mathrm{~km}^{2}$ in extent, historically vulnerable to such kind of phenomena (Figure 5a).

\subsection{Data}

For the study the following data were used and incorporated to GIS environment:

- 4 multispectral Landsat 5 TM, Landsat 7 ETM+ and Quickbird images. Specifically:

1. 1990-08-04 / Landsat 5- TM

$\underline{\text { XLVII, No } 3-1449}$ 
2. 2000-09-24 / Landsat 7 - ETM+

\section{2010-08-27 / Landsat 5-TM}

4. A panshapened Quickbird image (0.6 m resolution - VIS, NIR part of spectrum) of 2010.

- A Digital Elevation Model (DEM) of $25 \mathrm{~m}$ pixel size was used to generate geomorphologic parameters (slope, aspect and drainage network).

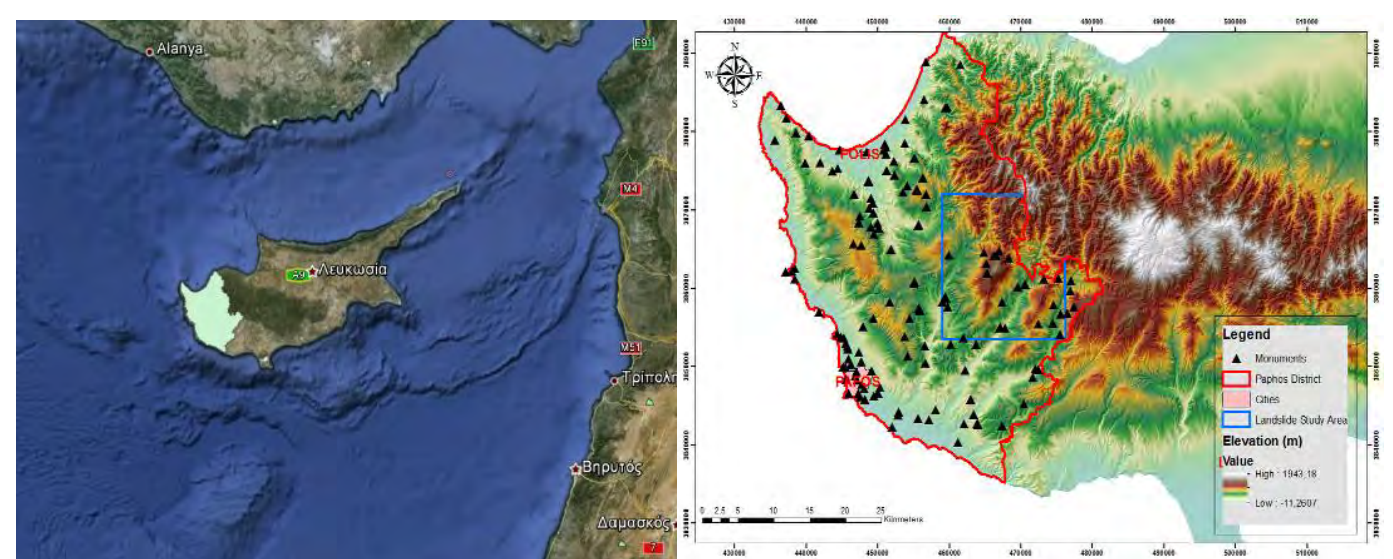

Figure 1 - Island of Cyprus (a). Study area (b).

\section{Methodology}

In order to map all known sites and monuments of Paphos District the necessary raw data from the Department of Antiquities of Cyprus were used. The authors explored the database of the «Cyprus Archaeological Digitization Programme», while at the same time all known sites were mapped using a customized GIS geodatabase. In total more than 170 monuments and sites exist in Paphos District (Figure 2b).
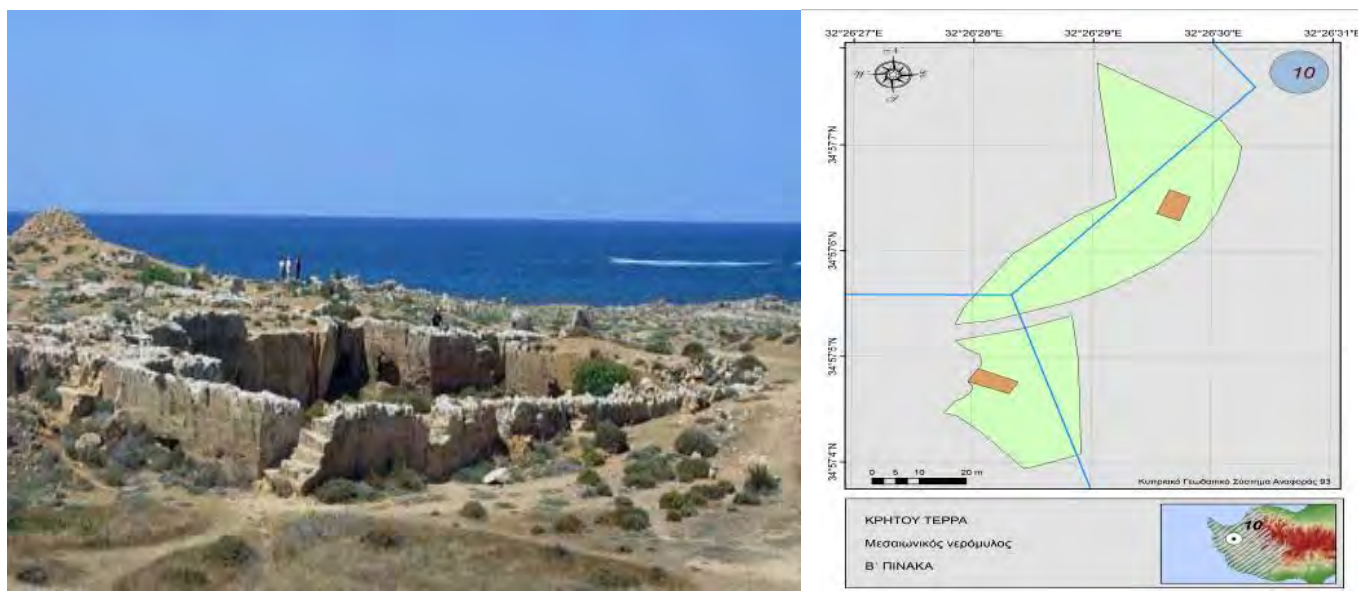

Figure 2 - Nea Paphos archaeological site (a). Digitization of cadastral maps in GIS environment (b).

After the construction of the archaeological database the research team proceeded to the natural and human risk assessment of Paphos archaeological sites in a threefold way: a) Evaluation of urban sprawl phenomenon and its impact to the archaeological sites, b) Estimation of erosion 
hazard potential in the whole Paphos district c) Landslide hazard assessment in the eastern part of Paphos district.

For the urban sprawl phenomenon, besides the SVM classification algorithm, the Stohastic Markov Chain model was also applied in order to predict urban expansion tendency for 2020. The Markov chain equation was constructed using the land cover distributions at the beginning (Mt) and at the end $(\mathrm{Mt}+1)$ of a discrete time period as well as a transition matrix (MLc) representing the land cover changes that occurred during that period. The transition probability matrix records the probability that each land cover category will change to every other category. The extracted land use map of 2020 was added to the landslide hazard model of 2020. In addition AHP (Analytical Hierarchical Process) was applied to develop the landslide model. The AHP is a flexible way o $\mathrm{f}$ analyzing complicated and multi criteria problems. According to the specific methodology the final weight of significance for each factor can be defined using the eigen-vectors of a square reciprocal matrix of pairwise comparisons between the different factors.

Concerning satellite images preprocessing steps, geometric corrections were carried out using standard techniques with several ground control points (GCP's) and a second order polynomial fit. Following, atmospheric corrections were applied to satellite images. As it is shown by several studies (Hadjimitsis et al., 2004) darkest pixel (DP) atmospheric correction methodology can be easily applied either by using dark targets located in the image or by conducting in situ spectroradiometric measurements.

\section{Urban Sprawl Phenomenon}

Initially several classification algorithms were applied to multitemporal Landsat TM images. Maximum likelihood, ISODATA, Nearest neighbour, SAM as well as SVM algorithms were implemented with the SVM algorithm to be proved to be the more accurate (Kappa coefficient accuracy ranges from 88-95\%). As Heumann (2011) argues, SVM can be used for remote sensing applications, for classification of either multispectral or hyperspectral data, in which spectral separability is less than perfect. The basic difference of SVM comparedto other classifiers, is the fact that SVM aims to identify the boundary between classes in n-dimensional spectral-space rather that assigning points to a class based on mean values.

For that purpose classification analysis was applied to the images of 1984, 2000 and 2010. The Landsat dataset was classified into four main land cover types (built up areas; water bodies; vegetation and land) for all the three images. The classification results were examined in order to evaluate the urban expansion in the vicinity of the cultural heritage sites of Paphos (Figure 3a). A buffer zone of $500 \mathrm{~m}$ around each monument was isolated and the percentage of each main land use class was calculated. The results indicated that the urban land cover in the vicinity of cultural heritage sites is increased during the period $1984-2010$. Specifically, urban expansion has been increased by $350 \%$ during the last 35 years. For the period 1984 until 2010, the new built up areas were found mainly in previous land classified areas $(70 \%)$ while other built up areas have replaced vegetation land cover (15\%). These land use change corresponds to approximately $51 \mathrm{~km}^{2}$ and 9 $\mathrm{km}^{2}$ for land and vegetation coverage respectively.

As it was proved a dramatic expansion was made especially during the last 10 years (2000-2010) in this region. Based on the results of SVM classification algorithm for 2000 and 2010 and with the use of Markov chain mode, an attempt was also made for the prediction of urban areas 2020. As it was proved (Figure 3b), the urban sprawl phenomenon will continue to expand and therefore the Paphos District archaeological sites and monuments will continue to suffer from the urban pressure. 


\subsection{RUSLE Methodology}
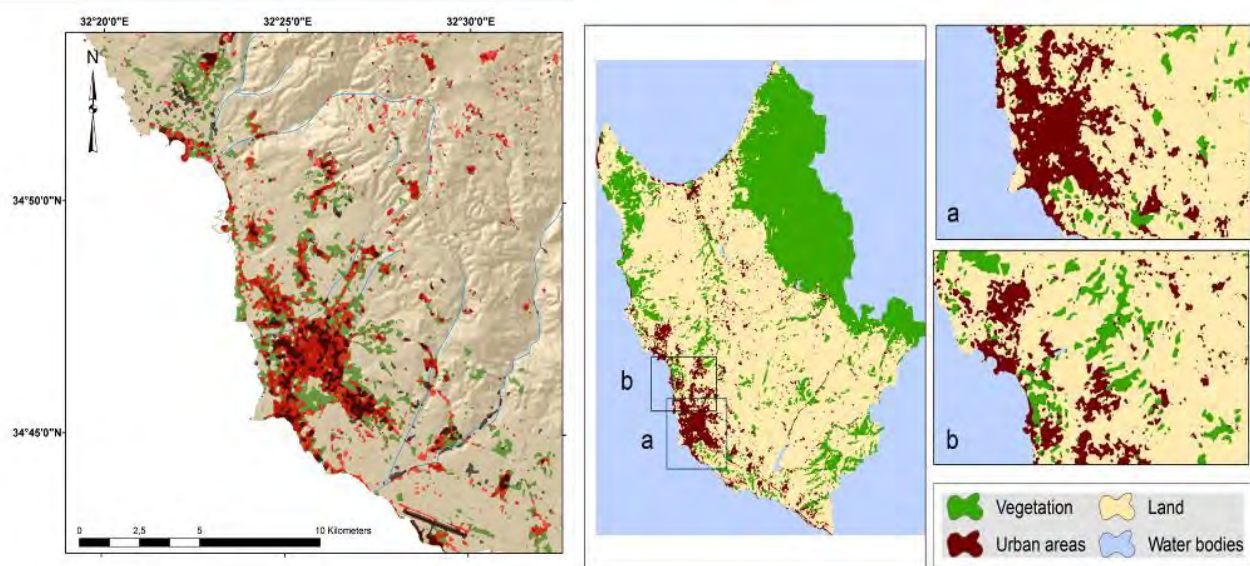

Figure 3 - Urban expansion of the Paphos city from 1984 to 2010. Black colour indicate urban areas back in 1984; orange colour the urban areas of 1990; red colour the urban areas of 2000 and green colour the urban areas of $\mathbf{2 0 1 0}$ (a). Built up areas in red as calculated from the Markov model for 2020 (b).

\section{Equation 1 -RUSLE equation}

$$
A=R * K * L * S * P
$$

where $A$ is the soil loss in $\mathrm{tha}^{-1}$ year ${ }^{-1}$ K $\mathrm{K}$ is the soil erodibility factor ( $\mathrm{t}$ ha h ha $\mathrm{ha}^{-1} \mathrm{~mm}^{-1}$ ), $R$ is the rainfall - runoff erosivity factor in $\mathrm{MJ} \mathrm{mm} \mathrm{ha} \mathrm{mm}^{-1} \mathrm{hear}^{-1} ; S$ is the slope steepness factor; $P$ is the conservation practices factor $\mathrm{r}$; $L$ is the slope length factor and $C$ is the cover and management factor.

\subsubsection{Rainfall (R) Factor}

The rainfall $R$ factor is a measure of the erosive force of a specific rainfall. The Modified Fournier Index (MFI) is well correlated with the rainfall erosivity. The specific index is considered as an eff ective estimator of $R$ factor because it takes into account the rainfall seasonal distribution. For the calculation of the $R$ factor with the use of the Modified Fournier Index (MFI), two different approa ches were used (Equation 2).

\section{Equation $2-\mathbf{R}$ factor}

$R_{1}=0.6120 * M F I^{1.56}$

$R_{2}=0.264 * M F I^{1.50}$

The MFI was applied to take into account the monthly rainfall distribution during each year for a period of 20 years.

Equation 3 - R factor Regression Analysis

$$
\text { MFI }=\sum_{J=1}^{N} \frac{F_{a j}}{N}=\frac{1}{N} \sum_{\mathrm{j}=1}^{N} \sum_{i=1}^{12} \frac{p_{i j}^{2}}{P_{j}}
$$

Where, $\mathrm{p}_{\mathrm{ij}}$ is the rainfall depth in month / $(\mathrm{mm})$ of the year $j$ and $P$ is the total rainfall for the same year. Then, the $R$ factor was estimated for both equations (Equation 2) and its mean value was 
finally calculated. After the calculation of the $R$ factor for the area's rain-gauge stations, a continue surface was produced using the point data of the stations and the Kriging interpolation method in GIS (Figure 4a).

\subsubsection{Soil Erodibility Factor (K)}

The soil erodibility factor $(K)$ refers to the average long-term soil and soil profile response to the erosive power associated with rainfall and runoff.

It is also considered to represent the rate of soil loss per unit of rainfall erosion index for a specific soil. A digital soil map of the study area was used and the main soil formations were categorized to 5 different major classes: coarse sandy loam, sandy loam and silty clay. According to Karydas et al., (2009) and Prasannakumar et al., (2011), the estimated $K$ values of the textural groups vary

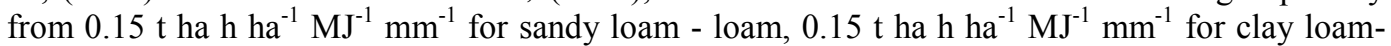

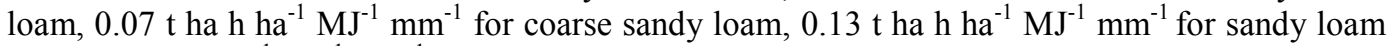
and $0.26 \mathrm{tha} \mathrm{h} \mathrm{ha}{ }^{-1} \mathrm{MJ}^{-1} \mathrm{~mm}^{-1}$ for silty clay (Figure $4 \mathrm{~b}$ ).

\subsubsection{Topographic Factor (LS)}

The topographic factor is related to the slope steepness factor $(S)$ and slope length factor $(L)$ and is considered to be a crucial factor for the quantification of erosion due to surface run - off. The com bined $L S$ factor was calculated by means of ArcGIS spatial analyst and Hydrotools extension librar $\mathrm{y}$. In this study the equation 4 was adopted.

Equation 4 - LS factor

$$
L S=\left(\frac{[\text { FlowAccumulation } * \text { Cellsize }]}{22.13}\right)^{0.4} *\left(\frac{\text { sin slope }}{0.0896}\right)^{1.3}
$$

\subsubsection{Practice Factor $(P)$}

Practice factor $(P)$ is defined as the ratio of soil loss after a specific support practice to the corresponding soil loss after up and down cultivation. In order to delineate areas with terracing practices the Quickbird satellite images were used and the delineation was accomplished in GIS environment with extensive monitoring of the study area. Areas with no support practice were assigned with a $P$ factor equal to 1 . On the other hand the terrace areas which are considered to be less prone to erosion were assigned a 0.55 value according to expert's opinion (Figure 4c).

\subsubsection{Cover Management Factor (C)}

$C$ factor represents the effect of soil-disturbing activities, plants, crop sequence and productivity le vel, soil cover and subsurface bio-mass on soil erosion.

The NDVI extracted from the study area (applied to Landsat 7 ETM+ image) has values that rang e from -0.65 to 0.99 . The NDVI is used along with the equation 5 in order to calculate the $C$ factor values of the study area in GIS environment.

\section{Equation 5 - P factor}

$$
C=\exp \left[-a \frac{N D V I}{(b-N D V I)}\right]
$$

where $\mathrm{a}$ and $\mathrm{b}$ are unitless parameters that determine the shape of the curve relating to NDVI and $C$ factor. According to the final results the $C$ factor values range from 0,67 to 1.26 . 


\subsection{RUSLE Model Results}

After the development of all the digital layers in GIS environment, with the use of equation 1 and through the use of Boolean algebra the final erosion hazard map was developed (Figure 4d). In the final RUSLE grid file due to the speckle phenomenon a 3x3 majority filter was applied to reduce the influence of the phenomenon. According to the final results the vast majority of sites are established on areas with recorded soil loss greater than the mean value soil loss of the whole district in tones/hectare * year.
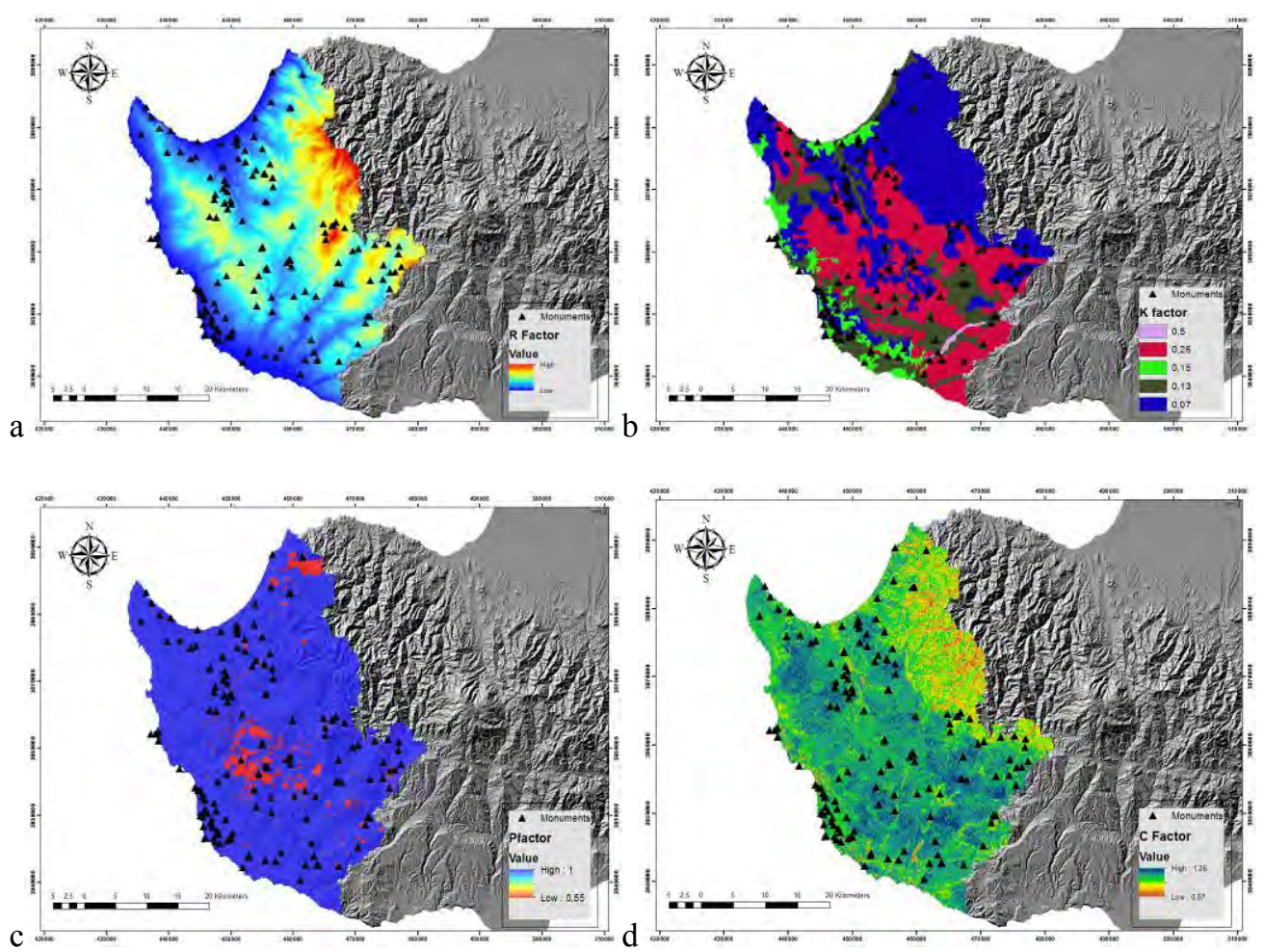

Figure 4 - $P$ factor (a). $K$ factor (b). $R$ factor (c). RUSLE model of the study area (d).

\section{Landslides Hazard Assessment}

Landslide occurrence depends on complex interactions among a large number of partially interrelated factors. Information from remotely sensed data is digitally processed and combined with other ancillary environmental information incorporated in a GIS. In total 9 factors were considered in calculating landslide probability: Distance from drainage network, distance from faults, slope, aspects, relief, lithology, precipitation and land use regime. These parameters were extracted either from the area's DEM (relief, aspect, slope), from image's classification (land use), from digitization of geological and topographic maps (lithology, faults, road network) or from provided from Cyprus Meteorological Service annual precipitation data and application of Kriging interpolation method. All the final 9 digital layers were implemented in GIS environment and reclassified with certain rates, according to experts' opinion, for their contribution to possible landslide phenomena (Figure $5 \mathrm{~b}$; c). In a next phase, AHP model was applied in order to compare the different parameters, their relative importance in estimating landslide risk and assign a final weight factor. 


\subsection{Implementation of AHP Methodology}

According to AHP methodology, pairwise comparison of the contribution of each factor was acco mplished. Specifically, answers of several experts were collected on the reciprocal matrix, and the appropriate eigenvector solution method was then employed to calculate the factor weightings. Spe cifically a certain grade is assigned to all the different pairs from 1/9 when the factor is "not import ant at all" to 9 when the factor is "extremely important" (Table 1)

Table 1 - Implementation of AHP method.

\begin{tabular}{|c|c|c|c|c|c|c|c|c|c|c|c|}
\hline Factors & F1 & F2 & F3 & F4 & F5 & F6 & F7 & F8 & F9 & $\begin{array}{c}\text { Total } \\
\text { Sum }\end{array}$ & $\begin{array}{c}\text { Normalized } \\
\text { Weights }\end{array}$ \\
\hline Lithology (F1) & 1 & 5 & 5 & 3 & 9 & 7 & 5 & 9 & 3 & 47 & 0.245 \\
\hline Land Use (F2) & $1 / 5$ & 1 & 3 & $1 / 3$ & 7 & 3 & 3 & 5 & $1 / 3$ & 22.86 & 0.119 \\
\hline $\begin{array}{c}\text { Distance from } \\
\text { Streams (F3) }\end{array}$ & $1 / 5$ & $1 / 3$ & 1 & $1 / 5$ & 5 & 3 & 3 & 5 & $1 / 3$ & 18.06 & 0.094 \\
\hline Slope (F4) & $1 / 3$ & 3 & 5 & 1 & 7 & 7 & 5 & 7 & 3 & 38.33 & 0.20 \\
\hline Aspect (F5) & $1 / 9$ & $1 / 7$ & $1 / 5$ & $1 / 7$ & 1 & $1 / 3$ & $1 / 5$ & 3 & $1 / 7$ & 5.12 & 0.026 \\
\hline $\begin{array}{c}\text { Precipitation } \\
\text { (F6) }\end{array}$ & $1 / 7$ & $1 / 3$ & $1 / 3$ & $1 / 7$ & 3 & 1 & $1 / 3$ & 3 & $1 / 7$ & 8.41 & 0.043 \\
\hline $\begin{array}{c}\text { Distance } \\
\text { from road } \\
\text { network (F7) }\end{array}$ & $1 / 5$ & $1 / 3$ & $1 / 3$ & $1 / 5$ & 5 & 3 & 1 & 5 & $1 / 5$ & 15.26 & 0.079 \\
\hline $\begin{array}{c}\text { Relative } \\
\text { Relief (F8) }\end{array}$ & $1 / 9$ & $1 / 5$ & $1 / 5$ & $1 / 7$ & $1 / 3$ & $1 / 3$ & $1 / 5$ & 1 & $1 / 7$ & 2.65 & 0.013 \\
\hline
\end{tabular}

After the calculation of the normalised weights, the consistency of the responses must be checked by calculating the Consistency Ratio. For that reason the Consistency index (CI) was calculated ac cording to equation 6 :

\section{Equation 6 - Consistency index}

$C I=\frac{\lambda \max -n}{n-1}=\frac{9.656-9}{9-1}=0.082$

Where $\lambda \max$ is the largest eigenvector and $\mathrm{n}$ is the number of criteria used in the study. The $\lambda \max$ value was calculated with the use of Matlab software. The final consistency ratio (CR) was estimat ed through the equation 7 :

Equation 7 - Consistency ratio

$C R=\frac{C I}{R I}=\frac{0.12}{1.45}=0.082$

where $R I=$ Random Consistency Index. For the case of 9 different factors is equal to 1,45 . Accordi ng to Saaty (1980) if that ratio exceeds 0.1 the set of judgments may be too inconsistent to be reliable. The Landslide Susceptibility Map with the corresponding weights of significance was calculated according to equation 8 :

Equation 8 - Landslide susceptibility map equation

$$
\begin{aligned}
\text { Landslide Susceptibility Map }= & F_{I^{*}} 0.245+F_{2} * 0.119+F_{3} * 0.094+F_{4} * 0.20+F_{5} * \\
& 0.026+F_{6} * 0.043+F_{7} * 0.079+F_{8} * 0.013+F_{9} * 0.176
\end{aligned}
$$

Following, the initial hazard map was then transformed to Landslide Hazard Zonation Map (LHZM) (Figure 5d). Thus, the digital GIS layer was reclassified in GIS environment according to 
Natural Breaks method to five major classes: Very High Hazard, High Hazard, Moderate Hazard, Low Hazard and Extremely Low Hazard. Over the final LHZM the digital road network was superimposed. Searching the results in GIS environment it was indicated that the vast majority of sites are established on areas of either High Hazard or Very High Hazard highlighting the vulnerability of sites in this specific natural threat.

Finally, the land use map of 2020 was incorporated in the final AHP model, which was implemented once again for 2020 period this time. The final results highlight a slight tendency for minimizing the landslide vulnerability of the study area.
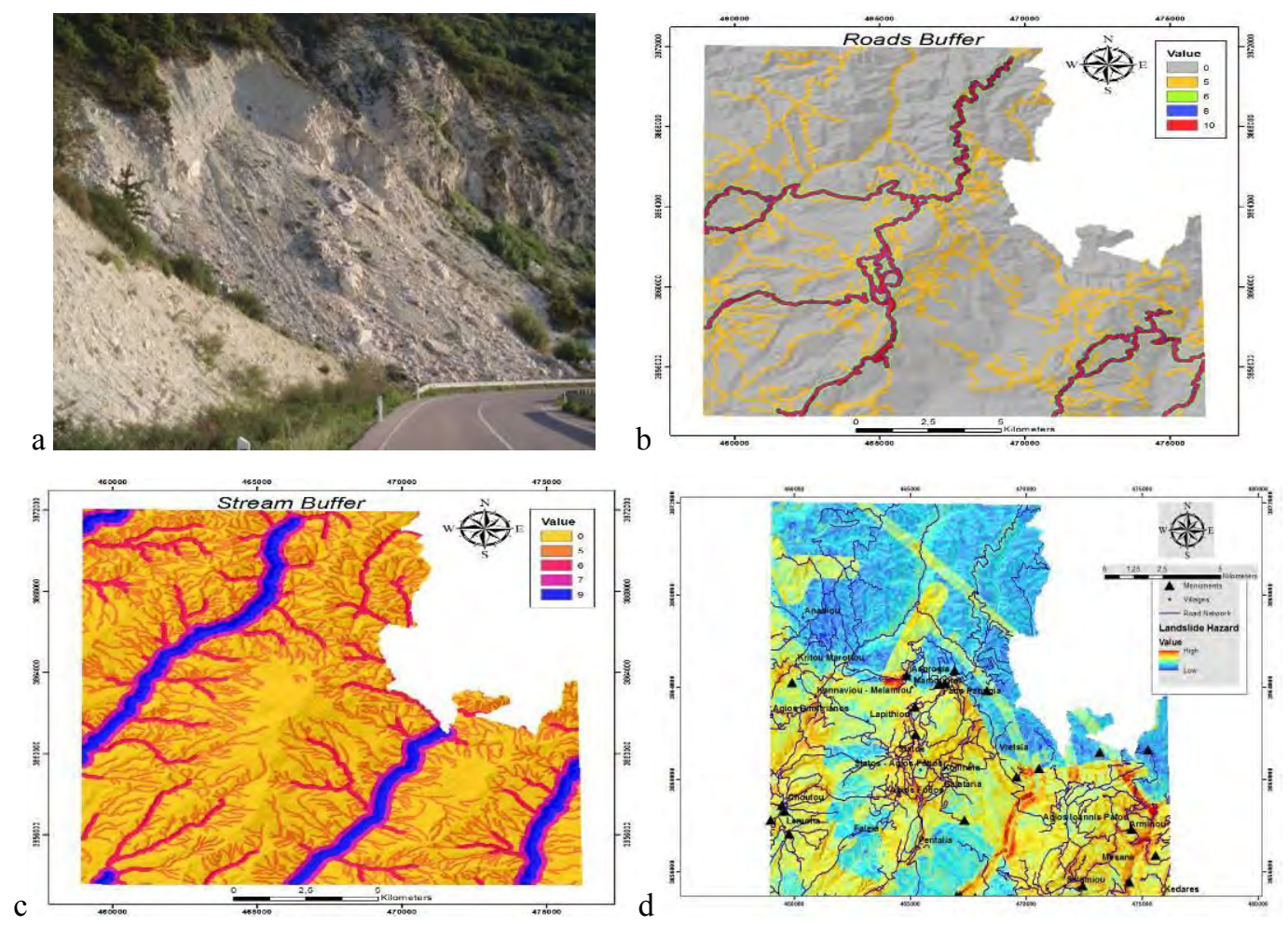

Figure 5 - Rock slide in chalk across a roadcut (a). Road buffer (b). Stream buffer (c). Landslide hazard assessment map (d).

\section{Results}

The environmental and human factors can contribute with equal or different participation to the damage of precious archaeological monuments and cultural reserves. The beneficial integrated use of satellite remote sensing with GIS has been demonstrated in this study for exploring the natural and anthropogenic hazard risk of the most significant cultural heritage sites in Paphos district in Cyprus.

As it was found, during the last years the phenomenon of urban sprawl has been recorded in the broader area of Paphos. Extensive construction and building development has taken place, and several areas of archaeological interest suffer from extensive urban pressure and the phenomenon is expected to intensify the next years. It was also proved vast number of sites is established on areas prone to erosion and landslide phenomena.This specific study revealed the different kind of natural and anthropogenic hazards that threatens the preservation of valuable $\mathrm{CH}$ sites. Additionally, this study provides the authorities with the essential knowledge that can help them to specify the actions they need to take for the protection of national heritage from natural 
phenomena and anthropogenic impacts. The research team will continue the relevant study by supplementing the model with more potential hazards and proceeding to a final integrated model of overall hazard of Paphos archaeological sites.

\section{Acknowledgments}

The results reported here are based on findings of the Cyprus Research Promotion Foundation project "AEIФOPIA/KOIA $\Phi / 0311(\mathrm{BIE}) / 06$ ". The project is funded by the Republic of Cyprus and the European Regional Development Funds. Thanks are also given to the Remote Sensing and Geo-Environment Laboratory of the Department of Civil Engineering \& Geomatics at the Cyprus University of Technology for its continuous support (http://www.cut.ac.cy). The authors would like to thank the Director of the Department of Antiquities Dr. Maria Hadjicosti for her permission to access the data of the Department.

\section{References}

Agapiou A., Hadjimitsis D.G., Alexakis D.D. and Papadavid G. 2012. Examining the phenological cycle of barley (hordeum vulgare) using satellite and in situ spectroradiometer measurements for the detection of buried archaeological remains, GIScience and Remote Sensing, 49(6), 854-872.

Alexakis D., Agapiou A., Hadjimitsis D. and Sarris A. 2012. Chapter: Remote sensing applications in archaeology, Remote Sensing/Book 2 (ISBN 979-953-307-231-8), Book edited by: Boris Escalante.

Canuti P., Casagli N., Catani F. and Fanti R. 2000. Hydrogeological hazard and risk in archaeological sites: some case studies in Italy, Journal of Cultural Heritage, 1, 117 - 125.

Carlon C., Marcomini A., Fozzati L., Scanferla1 P., Bertazzon S., Bassa1 S., Zanovello F., Stefano F., Chiarlo R. and Penzo F. 2002. ArcheoRisk: a Decision Support System on the Environmental Risk for Archeological Sites in the Venice Lagoon, Proceedings of the 1st Biennial Meeting of the iEMSs, Lugano, Switzerland.

Hadjimitsis D.G., Clayton C.R.I. and Hope V.S. 2004. An assessment of the effectiveness of atmospheric correction algorithms through the remote sensing of some reservoirs, Int. J. Remote Sens, 25, 3651-3674.

Hadjimitsis D.G., Agapiou A., Alexakis D. and Sarris A. 2013. Exploring natural and anthropogenic risk for cultural heritage in Cyprus using remote sensing and GIS, International Journal of Digital Earth, 6(2), 115-142.

Heumann B.W., 2011. An Object-Based Classification of Mangroves Using a Hybrid Decision Tree-Support Vector Machine Approach, Remote Sensing, 3, 2440-2460.

Karydas C., Sekuloska T. and Silleos, G. 2009. Quantification and site-specification of the support practice factor when mapping soil erosion risk associated with olive plantations in the Mediterranean island of Crete, Environ Monit Assess., 149, 19-28, DOI 10.1007/s10661-0080179-8.

Prasannakumar V., Vijith H. and Geetha N. 2011. Estimation of soil erosion risk within a small mountainous sub-watershed in Kerala, India, using Revised Universal Soil Loss Equation (RUSLE) and geo-information technology, Geoscience Frontiers, doi:10.1016/j.gsf.2011.11.003.

Saaty T. L. 1980. The Analytic Hierarchy Process, McGraw Hill International.

Sarris A., Topouzi S., Chatziiordanou E., Liu J. and Xu L. 2002. Space technologies in archaeological research \& CRM of semi-arid \& desertification affected regions. Examples from China \& Greece, European Space Agency, (Special Publication) ESA SP, (515), 185-188.

Themistocleous K., Nisantzi A., Agapiou A., Alexakis D. Hadjimitsis D., Lysandrou V., Perdikou S., Retalis A. and Chrysoulakis N. 2012. Long term monitoring of air pollution on monuments and cultural heritage sites in Cyprus using satellite remote sensing, International Journal of heritage in the digital Era, 1(1), 145-167.

XLVII, No $3-1457$ 